\title{
AUSÊNCIAS E POSSIBILIDADES: OS GUARDADOS DE JESSY CHEREM
}

\author{
ABSENCES AND POSSIBILITIES: THE STORIES OF JESSY CHEREM
}

\author{
Susane da Costa Waschineski ${ }^{1}$
}

RESUMO: Este texto pretende comunicar as possibilidades de pesquisa por meio dos arquivos pessoais da professora primária catarinense e bolsista do Programa de Assistência Brasileiro- Americana de Ensino Elementar (PABAEE), Jessy Cherem (1929-2014). A investigação centra-se na possibilidade de acessar os documentos, como cartas, recortes de jornais, álbuns fotográficos, certificados e diplomas, que permitam perceber a trajetória docente de Jessy Cherem, bem como mapear a circulação das ideias pedagógicas no âmbito do PABAEE e da História da Educação catarinense entre os anos de 1956 e 1964.

Palavras-chave: Arquivos pessoais. História da educação. PABAEE.

ABSTRACT: This text intends to communicate the possibilities of research through the personal archives of the primary teacher of Santa Catarina and scholarship holder of the Brazilian-American Assistance Program of Elementary Education (PABAEE), Jessy Cherem (1929-2014). The research focuses on the possibility of accessing documents, such as letters, newspaper clippings, photo albums, certificates and diplomas, which allow the reader to perceive the teaching career of Jessy Cherem, as well as to map the circulation of pedagogical ideas within PABAEE and History of Education in Santa Catarina between 1956 and 1964 .

Keywords: Personal archives. History of education. PABAEE.

\section{INTROUDÇÃO}

Pesquisas em arquivos pessoais permitem a problematização de vários aspectos em torno da acumulação documental e nos remetem às peculiaridades das ações cotidianas, compostas de guardados pessoais, como diários, álbuns de fotografia, cartas, bilhetes, comprovantes de passagens, entre muitos outros. Elas nos permitem indagar os responsáveis por esses arquivos, suas identidades e subjetividades, compondo aspectos da vida cotidiana, decifrando suas redes de sociabilidades. Levam-nos a pesquisar, também, quais foram os motivos que os levaram a guardar tais documentos e objetos, além dos fatores que levam a determinadas escolhas e seleção desses guardados.

Philippe Artières (1998) nos leva a refletir sobre os guardados que acumulamos ao longo de nossas vidas: e se pudéssemos, por um instante, reunir todos os objetos que já passaram por nossas mãos e de alguma forma compuseram alguns aspectos da nossa trajetória de vida? $\mathrm{E}$

\footnotetext{
I Doutoranda no Programa de Pós-Graduação em Educação na Universidade do Estado de Santa Catarina UDESC.
} 
ainda: e se realizássemos uma seleção, guardando apenas aquilo que possui mais significado e lembrança, como se pudéssemos arquivar parte de nossas vidas. O que esses guardados diriam sobre nós?

Certamente diriam muitas coisas, ao mesmo tempo em que muitos aspectos seriam indecifráveis, momentos repletos de ausências, marcados por aquilo que queremos esquecer ou, ao menos, guardar em um lugar que julgamos ser o mais seguro: a nossa memória. Isso nos leva às seguintes reflexões: quantos segredos guardamos ao longo da nossa vida? Como nossas vidas ficam expostas após a nossa morte?

Nesse processo de arquivar a própria vida, realizamos escolhas daquilo que se pretende lembrar e esquecer. Artières (1998, p. II) aponta para a existência das subjetividades que compõem os arquivos pessoais:

[...] não pomos nossas vidas em conserva de qualquer maneira; não guardamos todas as maçãs da nossa cesta pessoal; fazemos um acordo com a realidade, manipulamos a existência: omitimos, rasuramos, riscamos, sublinhamos, damos destaque a certas passagens.

Essa triagem, feita ao longo da acumulação documental, sofre ainda mais interferências após a nossa morte, pois aqueles que agora "limpam as gavetas" (ARTIÈRES, 1998, p. Io) os fazem com outros critérios de seleção.

O resultado dessa acumulação documental se apresenta aos pesquisadores de diferentes áreas, bem como define Arlete Farge (2009): é um local do paradoxo, dado que "[...] por mais que existam milhares de pilhas de denúncias, que as palavras a recolher pareçam impossíveis de se esgotar, um dia a falta, paradoxalmente, opõe sua presença enigmática" (FARGE, 2009, p. 58).

Inúmeras pesquisas são marcadas também pela ausência, seja por documentações específicas que sofreram pela ação da seleção, seja pelo tempo, ou ainda pela posse de familiares que, por motivos de luto, não conseguem ainda permitir que pesquisadores realizem consultas, ou porque simplesmente foram descartados após a morte.

Ao lidar com a ausência, realizo minha pesquisa neste momento de questionamento a respeito dos desafios de escrever sobre uma professora primária, de quem tenho algumas informações desencontradas. Questionada pelas possibilidades de investigação que podem se abrir a partir do contato com os arquivos pessoais de Jessy Cherem, resolvi refletir sobre essas possibilidades de pesquisa para explicar, em algumas linhas, como se desencadeou o interesse em biografá-la. 
I Jessy Cherem: pesquisando a partir dos vestígios documentais

Durante as investigações para a construção de minha dissertação, sob o título "Biblioteca de Orientação da Professora Primária: as regras de civilidade no conteúdo de Estudos Sociais do Programa de Assistência Brasileiro-Americana ao Ensino Elementar - PABAEE (1956-1964)", me dediquei em pesquisar o que foi o $\mathrm{PABAEE}$, os preceitos de civilidade, difundidos por meio dos manuais da "Biblioteca de Orientação da Professora Primária" e, em especial, o volume de Estudos Sociais.

O PABAEE surge no contexto dos anos de 1950, quando os discursos da época estavam encharcados das ideias desenvolvimentistas e de modernização. Nesse cenário, em 22 de junho de 1956, foi firmado o acordo entre Brasil e Estados Unidos, que previa o início da execução do Programa e cuja sede foi o Instituto de Educação de Belo Horizonte, no período de 1956 a 1964, normatizado pela Portaria do MEC no 7, de 1957, e pelo Decreto Legislativo no 16 , de 1965 (PAIVA; PAIXÃO, 2002).

Seus objetivos eram: garantir melhorias no ensino primário, indicando para a necessidade de superação do problemático quadro da época, a fim de diminuir os índices de evasão e elevado número de repetência; suprir a necessidade de treinamento de professores (as) das escolas primárias e normais de todo o país; produzir os materiais didáticos.

$\mathrm{Um}$ dos interesses que surgiram ao longo da pesquisa foi buscar identificar as docentes que participaram dos cursos de aperfeiçoamento do PABAEE, se havia professoras catarinenses e suas trajetórias profissionais após a participação nele.

Pude evidenciar, por meio do relatório do PABAEE apresentado por Paiva e Paixão (2002), que 864 bolsistas realizaram os cursos de aperfeiçoamento entre os anos de 1959 e 1964, representando 25 estados brasileiros, o que demonstra a abrangência do Programa em território nacional. O relatório aponta que, naquela época, 19 professoras de Santa Catarina estiveram em Belo Horizonte e possivelmente nos Estados Unidos, para onde foi quem se destacou e recebeu o convite para realizar aperfeiçoamento: "Foram distribuídas 142 bolsas de estudos para realização de cursos nos EUA. Alguns brasileiros obtiveram duas bolsas em períodos diferentes. I30 dessas bolsas foram para cursos na Universidade de Indiana e I2 em outras universidades" (PAIVA; PAIXÃO, 2002, p. 150).

Ao buscar informações referentes à participação das professoras catarinenses, encontrei algumas pistas nos seguintes estudos: "O Programa Brasileiro-Americano de Assistência ao Ensino Elementar (PABAEE) segundo memórias de uma aluna/professora", de Neide de Almeida Fiori (2007), e na pesquisa intitulada "Jessy Cherem: a construção da trajetória de uma educadora em Criciúma na década de 1960", da pesquisadora Angélica da Silva Goulart (2012). 
Por meio dessa pesquisa, que não tinha objetivo de enfatizar o PABAEE, pude garimpar pistas sobre o Programa em questão, além de vestígios da trajetória docente de Jessy Cherem.

Em meio à pesquisa de Goulart (2012), descobri que Jessy Cherem nasceu em Tijucas, região da Grande Florianópolis, e ainda recém-nascida se mudou com sua família para a capital catarinense, onde residiu por muitos anos e frequentou as aulas no Colégio Coração de Jesus, no qual se formou normalista.

Aos 22 anos, se casou e então foi morar em Curitiba, onde atuou no Colégio Divina Aquele que elson Providência, lecionando aulas particulares em sua casa para alunas que apresentavam dificuldade de aprendizagem. Treze anos depois, retorna a Florianópolis, assumindo uma função na Secretaria de Educação do estado de Santa Catarina (SED/SC), como funcionária concursada, ocasião na qual recebeu o convite para realizar o curso de aperfeiçoamento do PABAEE em Belo Horizonte.

Ela viajou à capital mineira em 1962, permanecendo um ano, quando realizou diversos cursos de aperfeiçoamento e se especializou em jardins de infância. Após concluí-los, retornou a Santa Catarina e, assim como as demais bolsistas, deveria trabalhar durante dois anos com a formação de professores(as) para o aperfeiçoamento e a difusão do conhecimento.

Isso acabou ocorrendo quando ela recebeu o convite para atuar como secretária da Educação do município de Criciúma, passando a morar na cidade em 1963. Lá, lecionou no Colégio Madre Tereza Michel, tradicional colégio católico de Criciúma e administrado pelas Pequenas Irmãs da Divina Providência, além de atuar na Secretaria da Educação.

Durante os anos que residiu em Criciúma, sua atuação transitou em duas frentes: na formação das professoras primárias e, em paralelo, na construção do primeiro jardim particular da cidade, que se chamou Jardim de Infância Pequeno Príncipe. Com essa implantação, Jessy pôde aplicar os conhecimentos adquiridos durante o curso de aperfeiçoamento do PABAEE e contribuir para trazer outros olhares para a educação criciumense.

Ela deixou a cidade de Criciúma e retornou a Florianópolis em 1967, continuando a exercer diversas atividades vinculadas à $\mathrm{SED} / \mathrm{SC}$ e à formação de professores(as). Foi presidente da Organização Mundial para Educação Pré-Escolar em Santa Catarina (OMEP/SC), órgão da Organização das Nações Unidas (Unesco) e do Fundo das Nações Unidas para Infância (Unicef) que promove a educação e a defesa dos direitos da criança. Também foi diretora do Museu Histórico de Santa Catarina (MHSC) desde a sua fundação (1976) até o ano de 1987.

Sua trajetória apresenta o trânsito de mulheres que "ousaram atravessar fronteiras" (ORLANDO; SILVA; DANTAS, 2015, p.7), construindo um intercâmbio de saberes. Em um 
período no qual viajar ou assumir cargos políticos ainda se apresentavam como feições dos homens, Jessy foi uma dessas mulheres que romperam com alguns padrões, questionando o lugar delas e as dimensões do público e do privado.

Professora primária, estudiosa da educação, atuou na formação de outras professoras, assumiu cargos públicos, circulou sobre determinados circuitos culturais. Foi alguém que guardou muitas lembranças e muitos papéis relacionados à sua formação profissional. Acumulou, ao longo desse percurso, diversos documentos, compondo seus próprios guardados, que ajudaram a compor, mesmo que de forma fragmentada, sua história de vida.

O conjunto desses documentos foi exibido pela própria Jessy Cherem, quando concedeu entrevista para Goulart (2012). Ele é composto majoritariamente por álbuns de fotografias, organizados por eventos relacionados à sua formação e atuação profissional, e também material escrito, desde pequenas marginálias (informando datas e nomes, em cadernos cuidadosamente organizados com colagens) até uma grande quantidade de certificados, recortes de jornais e cartas.

Essa coletânea demonstra sua preocupação, no processo de arquivar a própria vida, em coletar, selecionar e organizar informações geralmente sobre ela mesma ou sobre educacionais que havia estudado no PABAEE, cujos temas eram as formações destinadas aos(às) professores/as).

As pesquisadoras Ana Chrystina Venancio Mignot e Maria Teresa Santos Cunha (2006) comentam que guardar é uma forma de evitar o esquecimento, garantindo lugar na posterioridade. Um dos guardados que ganham mais espaço no arquivo pessoal de Jessy Cherem são as fotografias, que, segundo as mesmas autoras, permitem reunir determinados fragmentos da vida em pedaços de papel: "Eternizam momentos significativos, revelando espaços de atuação e desvelando estratégias adotadas para que a voz feminina se fizesse ouvir no debate educacional" (MIGNOT; CUNHA, 2006, p. 46-47).

Ela teria interesse em um dia contar sua história? Seria uma forma de se imortalizar? Gostaria de deixar um legado no campo da formação de professores (as) e na construção dos jardins de infância em Santa Catarina? Ela tinha dimensão da importância desses guardados para a História da Educação?

A ausência e as possibilidades de garimpar esses documentos me faz pensar sobre quem foi essa mulher. Como era vista ao chegar da capital para atuar na Secretaria de Educação de Criciúma, em um período no qual as mulheres não tinham muita representatividade nos cargos políticos e de gestão.

Questões surgem também sobre as 19 professoras normalistas catarinense que, 
certamente, assumiram cargos de responsabilidade e de destaque, dando mais visibilidade para as mulheres na educação. Como bem enfatiza Fischer (2005, p. 78), "Seus guardados de ontem agora ajudam a reconstruir excertos de vida desta mulher. Ao mesmo tempo permitem levantar questões a respeito de um momento vivido pelas professoras em suas práticas políticas”, pois registram particularidades que não podem ser captadas em documentos oficiais.

Essa ausência ressoa, no meu desejo como pesquisadora, em interrogar essas lembranças e viajar no tempo, permitindo encontrar pistas que me ajudem a compor esse emaranhado de relações que tento no momento articular, muitas vezes de forma exaustiva e frustrante.

Tomo como referência a pesquisa de Beatriz T. Daudt Fischer (2005): "As caixas de papéis de Nilce Lea: memórias e escritas de uma simples professora?". Fischer, investigando as caixas de documentos da professora, observou que havia fragmentos que "permitem não só visualizar a história de vida como também perceber um cenário político amplo, marcado por relações de micropoderes em confronto no interior do movimento docente, no final da década de 70 do século XX" (FISCHER, 2005, p. 69), no estado do Rio Grande do Sul.

A partir do estudo de Fischer (2005), me ponho a refletir: que enunciações os arquivos pessoais de Jessy Cherem podem permitir? O que eles podem me informar?

Outros estudos com arquivos pessoais, escritas ordinárias e autobiográficas vêm sendo desenvolvidos no Brasil, como o apresentado por Ana Chrystina Mignot e Elizeu Clementino de Souza (2015) em "Modos de viver, narrar e guardar: diálogos cruzados sobre pesquisa (auto)biográfica".

Outros que destaco são a pesquisa de Maria Teresa Santos Cunha (2017): "O arquivo pessoal do professor catarinense Elpídio Barbosa (1909-1966): do traçado manual ao registro digital", "Refúgios do eu: educação, história, escrita autobiográfica", coletânea organizada por Ana Chrystina Venancio Mignot, Maria Helena Camara Bastos e Maria Teresa Santos Cunha (200o), "Destinos das letras: história, educação, escrita epistolar", obra das autoras Bastos, Cunha e Mignot (2002) e "Histórias de vida e autobiografias na formação de professores e profissão docente (Brasil, 1985-2003)", artigo de Belmira Oliveira Bueno, Helena Coharik Chamlian, Cynthia Pereira de Sousa e Denice Barbara Catani (2006).

O conjunto dessas produções apresenta importantes contribuições para a História da Educação, pois traz à cena aspectos capturados nas sensibilidades, nas escritas e nos guardados pessoais desses (as) professores (as), valorizando as memórias e as experiências dos que viveram. Elas apresentam também caminhos e estratégias metodológicas utilizadas pelos (as) pesquisadores(as) ao estudarem esses documentos, contribuindo para o campo e fornecendo valiosas informações. 
2. Considerações finais

O gesto de arquivar a própria vida, segundo Artières (1998), não é privilégio apenas dos homens ilustres: todos nós, em algum momento das nossas vidas, por alguma razão, nos entregamos ao exercício de guardar.

Nesse movimento, os arquivos pessoais, muitos deles repletos dos chamados "egodocumentos" são frutos do processo de registro de guarda e seleção de muitos deles, ao longo de suas vidas, compondo um rico espaço de pesquisa para inúmeros pesquisadores - como é o caso dos arquivos pessoas de Jessy Cherem, os quais ainda não possuo localização certa, ou mesmo se continuam existindo. Chamo atenção para a importância da preservação e a disponibilização desses documentos para os pesquisadores, pois são informantes de trajetórias de vida, experiências profissionais, cenários políticos, frutos de uma época.

Nesta etapa, encontro-me envolvida pela curiosidade e pelas possibilidades que o acesso a esses documentos pode me apresentar, mirando o desenrolar de algumas informações e dos múltiplos enredos que já tratei de construir mentalmente. Entretanto, ponho-me novamente ao foco e busco avançar nas pesquisas com intuito de desvendar novas informações sobre as professoras catarinenses no PABAEE.

Referências

ARTIÈRES, P. Arquivar a própria vida. Revista Estudos Históricos, Rio de Janeiro, v. in, n. 2I,

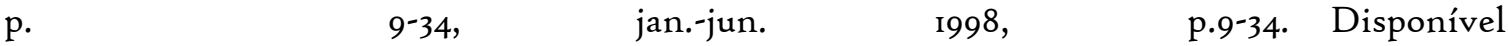
em:

〈http://bibliotecadigital.fgv.br/ojs/index.php/reh/article/view/206I/I200〉. Acesso em: I2 fev. 2018.

BASTOS, Maria Helena câmara; CUNHA, Maria Teresa Santos; MIGNOT, Ana Crystina Venâncio. (Org.). Destinos das letras: história, educação, escrita epistolar. Passo Fundo: EDu PF: 2003

BUENO, Belmira Oliveira et al. Histórias de vida e autobiografias na formação de professores e profissão docente (Brasil, 1985-2003). Educação e Pesquisa, v. 32, n. 2, p. 385-410, 2006. Disponivel em: $<$ http://www.scielo.br/pdf/ep/v32n2/ar3v32n2>. Acesso em 25 fev.2019.

CUNHA, Maria Teresa. Arquivo pessoal do Professor Catarinense Elpídio Barbosa (19091966): do traçado manual ao registro digital. Hist. Educ. (Online) Porto Alegre v. 2i n. 5I Jan./abr., $2017 \quad$ p. $\quad$ 187-206. $\quad$ Disponível em:< http://www.scielo.br/scielo.php?script=sci_arttext\&pid=S2236$34592017000100187 \& \operatorname{lng}=p t \& t \operatorname{lng}=p t>$. Acesso em: I5 jan 2019.

FISCHER, B. T. D. As caixas de papéis de Nilce Lea: memórias e escritas de uma simples professora? História da Educação, Pelotas, v. 9, n. 17, p. 69-8o, jan.-jun. 2005. Disponível em: 
$\langle$ http://seer.ufrgs.br/index.php/asphe/article/download/2920I/pdf $\rangle$. Acesso em: I2 fev. 2018.

GOULART, A. da Silva. Jessy Cherem: a construção da trajetória de uma educadora em Criciúma na década de 1960. 2012. 56 f. TCC (Graduação) - Curso de Pedagogia, Universidade do Extremo Sul Catarinense (Unesc), Criciúma, 2012. Disponível em:

〈http://repositorio.unesc.net/handle/I/r93/r/Ang\%c3\%a9lica\%2oda\%2oSilva\%Goulart.pdf . Acesso em: 28 dez 2019.

MIGNOT, A. C. V.; CUNHA, M. T. S. Razões para guardar: a escrita ordinária em arquivos de professores/as. Revista Educação em Questão, Natal, v. 25, n. II, p. 40-6I, jan.-abr. 2006. Disponível em: 〈https://peridoicos.ufrn.br/educacaoemquestao/artucke/view/8282/5959>. Acesso em: 12 fev 2019.

MIGNOT, Ana Chrystina; SOUZA, Elizeu Clementino de. Modos de viver, narrar e guardar: diálogos cruzados sobre pesquisa (auto)biográfica. Revista Linhas. Florianópolis, v. i6, n. 32, p. Io

$\langle$ http://www.revistas.udesc.br/index.php/linhas/issue/view/453)〉. Acesso em 26 fev. 2018.

ORLANDO, Evelyn de Almeida; SILVA, A. L. (Org.); DANTAS, Maria José (Org.). Mulheres em trânsito: intercâmbios, formação docente, circulação de saberes e práticas pedagógicas. I. ed. Curitiba: CRV, 2015. v. or. 245p.

PAIVA, E. V. de; PAIXÃO, L. P. PABAEE (1956-1964): a americanização do ensino elementar no Brasil? Niterói: UFF, 2002. 